\title{
Platelet deposition studies on copolyether urethanes modified with poly (ethylene oxide)
}

\author{
E. Brinkman, A. Poot, L. van der Does and A. Bantjes \\ Biomaterials Section, Department of Chemical Technology, Twente University of Technology, PO Box 217, 7500 AE \\ Enschede, The Netherlands \\ (Received 18 January 1989; revised 3 April 1989; accepted 9 April 1989)
}

\begin{abstract}
Pellethane ${ }^{\circledR} 236380 A$ films and tubings were chemically modified and the effect of these modifications on platelet deposition was studied. Grafting of high molecular weight poly(ethylene oxide) and graft polymerization of methoxy poly (ethylene glycol) $\mathbf{4 0 0}$ methacrylate resulted in surfaces with a good water wettability. The increased hydrophilicity of these modified surfaces could be demonstrated by contact angle measurements. The platelet deposition was investigated with tubings in a capillary flow system, using different types of perfusates. Platelet deposition from a buffer-containing perfusate on surfaces modified with either high molecular weight poly (ethylene oxide) or methoxy poly (ethylene glycol) $\mathbf{4 0 0}$ methacrylate was almost absent and less than on Pellethane 2363 80A. Using a citrated plasmacontaining perfusate the amount of deposited platelets on Pellethane 2363 80A modified with high molecular weight poly (ethylene oxide) was low and about the same as on unmodified surfaces. However, a marked reduced platelet deposition compared to unmodified Pellethane 2363 80A was found when the platelets were activated by $\mathrm{Ca}^{2+}$ ionophore. The improved blood compatibility of the modified Pellethane $236380 \mathrm{~A}$ tubings obviously indicates the favourable effect of the presence of grafted $\mathrm{PEO}$ on the surface.
\end{abstract}

Keywords: Copolyether urethanes, poly(ethylene oxide), grafting, platelet deposition

Poly(ethylene oxide) (PEO) is more and more regarded as a polymer with interesting blood contacting properties. The low affinity of PEO for proteins and other blood components has stimulated many investigators to study the interactions of blood and biomaterials based on PEO $^{1-7}$.

In an attempt to improve the blood compatibility of a commercial copolyether urethane, Pellethane ${ }^{\varpi} 236380 \mathrm{~A}$ (Pell 80A), several techniques for grafting PEO onto Pell 80A were investigated. Grafting of high molecular weight PEO with dicumyl peroxide (DCP) and graft polymerization of methoxy poly (ethylene glycol) 400 methacrylate (MPEGMA$400)$ were examined. The first method is based on crosslinking of high molecular weight polyethers. Cross-linked blends of poly (propylene oxide) and PEO have shown a good blood compatibility ${ }^{4}$. Surface analysis of these blends suggested that the good blood contacting properties of these materials may be ascribed to preferential presence of PEO at the polymer-water interface ${ }^{8}$. In the present work, Pell $80 A$ substrates were dipped in a solution of PEO and DCP. After drying, the PEO/DCP coated substrates were UV or heat treated in order to form a network of PEO and Pell

Correspondence to $\mathrm{Dr} L$. van der Does.
80A. Part of the work on heat treatment of PEO/DCP coated Pell 80A substrates has been reported previously ${ }^{9}$.

For the second approach, we studied the possible use of the controlled oxidation technique for grafting MPEGMA400. Using this method, graft polymerization of 2-hydroxyethyl methacrylate (HEMA) on to polyurethanes has been described by Feng et al. ${ }^{10}$. Because of the analogy in chemical structure between HEMA and MPEGMA-400, it was hypothesized that MPEGMA-400 could also be grafted by the controlled oxidation technique. However, Feng used relatively high initial monomer concentrations $(2 \mathrm{M})$ for the grafting of HEMA and these conditions cannot be applied for the graft polymerization of MPEGMA-400. The grafting of methacrylates at low initial monomer concentrations was therefore studied, using HEMA as a model compound for MPEGMA-400.

Modification of Pell $80 \mathrm{~A}$ films and tubings was investigated. Contact angles were determined to study the properties of modified films and tubings.

Finally, the effect of PEO modification of the luminal side of Pell 80A tubings on platelet deposition in vitro was investigated. The platelet deposition was studied in a capillary flow system, the characteristics of which have been described previously ${ }^{11}$.

1990 Butterworth \& Co (Publishers) Ltd. 0142-9612/90/030200-06 


\section{MATERIALS AND METHODS}

\section{Materials}

Pell 80A, obtained from Upjohn Polymers BV (Delfzijl, The Netherlands), was extruded and used for preparation of Pell $80 \mathrm{~A}$ films. Pell $80 \mathrm{~A}$ tubings $(0.8 \mathrm{~mm}$ i.d.). used for the platelet deposition studies, were obtained from B. Braun A.G. (Melsungen, FRG).

PEO $\left(\vec{M}_{w}=180000\right)$ was purchased from Polysciences Inc. (Warrington, MA, USA). The cross-linking agent DCP, obtained from Akzo (Deventer, The Netherlands), was used after repeated recrystallization from methanol. HEMA, used as a model compound for graft polymerization, was obtained from Merck (Darmstadt, FRG). The monomer, purified by extraction with cyclohexane and distillation, contained traces of methacrylic acid, but no ethylene glycol dimethacrylate. MPEGMA-400, obtained from Polysciences Inc. (Warrington, MA, USA), was used without purification.

\section{Characterization of modified films-contact angle measurements}

Contact angles were determined with the captive bubble method $^{12}$. The contact angle was taken from $\theta=$ arccos $(2 H / D-1)$ in which $H$ and $D$ are height and diameter of the air bubble. The contact angle was measured after $1 \mathrm{~h}$ contact with water. Only the air side of the film was investigated.

\section{Characterization of the luminal side of modified tubings-contact angle measurements}

Contact angles of the inner side of Pell 80A tubings were measured by capillary rise. From the height of the column in an equilibrium situation, $q$ can be calculated using the following equation:

$$
\cos \theta=\frac{\rho \mathbf{g} h r_{\mathrm{c}}}{2 \gamma_{\mathrm{L}}}
$$

where $\rho$ is the density of the liquid $\left(\mathrm{kg} / \mathrm{m}^{3}\right), \mathbf{g}$ is the gravitational acceleration $\left(\mathrm{m} / \mathrm{s}^{2}\right), h$ is the height of the liquid column $(m), r_{c}$ is the inner radius of the capillary $(m)$ and $\gamma_{L}$ is the surface tension of the liquid $(\mathrm{mN} / \mathrm{m})$. The capillary rise was measured after $24 \mathrm{~h}$ equilibration in water.

\section{Platelet deposition studies}

Platelet deposition on modified Pell 80A tubings was studied in a slightly modified version of the capillary flow system of Cazenave et al. ${ }^{13}$ using ${ }^{11}$ Indium-labelled human platelets. The perfusate was prepared in three ways. In the standard procedure ${ }^{11}$ washed platelets ${ }^{14}$ were resuspended in buffer after the last washing cycle (perfusate A). Alternative perfusates were prepared by resuspending the washed platelets in citrated plasma (perfusate B). Eventually, $\mathrm{Ca}^{2+}$ ionophore A 23187 (1 mM, Boehringer Mannheim, FRG) was added $2 \mathrm{~min}$ before the perfusion experiment (perfusate $\mathrm{C}$ (citrated plasma plus $\mathrm{Ca}^{2+}$ ionophore)), in order to activate the platelets.

Medical grade low density poly(ethylene) tubings $10.75 \mathrm{~mm}$ i.d., $30 \mathrm{~cm}$ long, Talas BV, Ommen, The Netherlands) were used as a reference material in this test. All tubings were rinsed with water for $24 \mathrm{~h}$ before the perfusion experiments. After perfusion $\left(37^{\circ} \mathrm{C}, 5 \mathrm{~min}\right.$, shear rate: $\left.250 \mathrm{~s}^{-1}\right)$ the amount of deposited platelets could be calculated by measuring the radioactivity of the tubings.

\section{Modification of films with poly (ethylene oxide)}

Pell 80A films, cast from $5 \%(\mathrm{w} / \mathrm{w})$ solutions in THF, were cut into pieces $(2 \times 4 \mathrm{~cm})$ and washed in methanol for $48 \mathrm{~h}$ in order to remove additives ${ }^{15,16}$. The washed films were dried overnight in a vacuum oven $\left(60^{\circ} \mathrm{C}\right)$. PEO was dissolved in methylene chloride; DCP, when used, was added to the $1 \%(w / w)$ PEO solution $(D C P=0.05 \%(w / w))$. Pell $80 A$ films were dipped in the PEO solution for $30 \mathrm{~s}$ and dried in air for $1 \mathrm{~h}$ at r.t. To initiate the cross-linking, the films were irradiated with UV (254 nm, Heraeus TNN 15/32, Hanau, FRG) in a nitrogen atmosphere for $1 \mathrm{~h}$ at r.t. or thermally treated in a vacuum oven at $130^{\circ} \mathrm{C}$ for $1 \mathrm{~h}$. PEO modified films were washed for $24 \mathrm{~h}$ either with water or methylene chloride. Water is a good solvent for PEO, but Pell 80A films do not swell in water. Therefore, this solvent may be ineffective in removing all the non-cross-linked PEO. Methylene chloride $\left(\mathrm{CH}_{2} \mathrm{Cl}_{2}\right)$ is also a good solvent for PEO and a strong swelling agent for Pell 80A. It is expected that $\mathrm{CH}_{2} \mathrm{Cl}_{2}$ is a more powerful extraction medium also for DCP and decomposition products. Finally, the films were dried in a vacuum oven $\left(40^{\circ} \mathrm{C}, 24 \mathrm{~h}\right)$.

\section{Modification of films by graft polymerization of methacrylates}

Graft polymerizations with HEMA and MPEGMA-400 were performed according to a slightly modified version of the procedure described by Feng et al.$^{10}$. Pell 80A films were stirred in a $30 \%(w / w) \mathrm{H}_{2} \mathrm{O}_{2}$ solution for $1 \mathrm{~h}$. Subsequently the $\mathrm{H}_{2} \mathrm{O}_{2}$ treated films were thoroughly washed with water for $1 \mathrm{~h}$.

For the grafting of HEMA or MPEGMA-400, aqueous solutions containing monomer $(0.05$ or $0.10 \mathrm{M})$, $\mathrm{FeSO}_{4} \cdot 7 \mathrm{H}_{2} \mathrm{O}(8 \mathrm{mM})$ and $\mathrm{H}_{2} \mathrm{SO}_{4}(0.05 \mathrm{M})$ were used. After bubbling $\mathrm{N}_{2}$ through the monomer solution for $20 \mathrm{~min}$, the films were stirred in the monomer solution for $1 \mathrm{~h}$ at r.t.. Finally, modified films were thoroughly washed with water for $72 \mathrm{~h}$. The water was refreshed every $24 \mathrm{~h}$. Washed films were dried in a vacuum oven overnight $\left(40^{\circ} \mathrm{C}\right)$.

\section{Modification of the luminal side of tubings by gratting of poly (ethylene oxide)}

Pell $80 A$ tubings $(0.8 \mathrm{~mm}$ i.d., length $30 \mathrm{~cm})$ were used as received (Pell $80 A$ ) or prerinsed with methanol for $48 \mathrm{~h}$ (Pell $80 \mathrm{~A}-\mathrm{MeOH})$ to remove additives. After rinsing, the tubings were dried in a vacuum oven $\left(60^{\circ} \mathrm{C}\right)$ overnight.

A solution of $\mathrm{PEO} / \mathrm{DCP}$ in methylene chloride was prepared as described before (PEO $1 \% \mathrm{w} / \mathrm{w}$, DCP $0.05 \%$ $w / w)$. The PEO/DCP solution was aspirated into the tubings (length $30 \mathrm{~cm}$ ) with a $10 \mathrm{ml}$ syringe. After $30 \mathrm{~s}$, the tubings were drained by gravity and dried in air. PEO coated tubings were thermally treated as described for surface modification of Pell 80A films. The thermally treated tubings (Pell 80A $\mathrm{PEO} / \mathrm{DCP})$ were washed with water $(24 \mathrm{~h}$ ) and acetone ( $2 \mathrm{~h})$ to remove non-cross-linked PEO, DCP and decomposition products, respectively.

\section{Modification of the luminal side of tubings by graft polymerization of MPEGMA-400}

Pell $80 \mathrm{~A}$ or Pell $80 \mathrm{~A}-\mathrm{MeOH}$ tubings were successively rinsed with a $30 \% \mathrm{H}_{2} \mathrm{O}_{2}$ solution ( $1 \mathrm{~h}$ ) and water $(1.5 \mathrm{~h})$. The monomer solutions and the tubings were flushed with nitrogen before the start of the grafting experiments (30 $\mathrm{min}$ ). Graft polymerization was started by pumping the 
monomer solution through the tubings at a constant speed $(1.5 \mathrm{ml} / \mathrm{min})$. The monomer solution was circulated for $1 \mathrm{~h}$. Finally, modified tubings (Pell 80A/MPEGMA-400) were rinsed with water for $24 \mathrm{~h}$.

\section{RESULTS}

\section{Modification of films with poly (ethylene oxide)}

Pell 80A films, cast from THF solutions, had contact angles of $60-65^{\circ}$. After washing with $\mathrm{MeOH}$ for $48 \mathrm{~h}$, values of $55-60^{\circ}$ were observed. In the absence of PEO and DCP, UV or heat treatment resulted in films showing about the same contact angle as untreated films (Table 1, experiments 1 and 2). When Pellethane films were modified in the presence of PEO and DCP UV as well as heat treatment, films were obtained with increased hydrophilicity (experiments 4,5 and 6). DCP was added to the PEO solution because it was expected to act as a cross-linker. However, from experiments 7, 8 and 9 , it can be seen that even without DCP, a substantial decrease of the contact angle was observed. Because $\mathrm{CH}_{2} \mathrm{Cl}_{2}$ was supposed to be more effective than water in removing uncross-linked PEO and decomposition products of DCP, films were treated identically, but after treatment washed with water or with $\mathrm{CH}_{2} \mathrm{Cl}_{2}$. However, the differences were small, as can be seen from experiments 2 and 3,5 and 6 and from 7 and 8 .

\section{Modification of films by graft polymerization of methacrylates}

Graft polymerization of HEMA on Pell 80A films was studied to obtain information on the grafting conditions for MPEGMA400. Although, even in the absence of HEMA, a decrease of the contact angle of the Pell $80 A$ films was observed, more hydrophilic surfaces were obtained using HEMA in concentrations of $0.05-0.10 \mathrm{M}$. Using the same conditions a large decrease of the contact angle was observed with MPEGMA400 with an initial concentration of $0.1 \mathrm{M}$ (Table 2).

\section{Modification of the luminal side of tubings}

The luminal side of the Pell $80 \mathrm{~A}$ tubings was modified with PEO/DCP (thermally induced cross-linking) and by graft polymerization of MPEGMA-400. A successful modification of the luminal side of the tubings could be qualitatively demonstrated by capillary rise (Table 3). It shows that PEO or MPEGMA-400 grafting only occurred with Pell $80 A$ tubings prerinsed with methanol (Pell $80 \mathrm{~A}-\mathrm{MeOH})$. From the height

Table 1 Contact angles of Pell $80 \mathrm{~A}$ films washed with $\mathrm{MeOH}$ and modified by PEO/DCP: effect of UV and heat treatment

\begin{tabular}{|c|c|c|c|c|c|c|}
\hline Experiment & PEO & DCP & UV & Heat & $\begin{array}{l}\text { Extraction } \\
\text { solvent }\end{array}$ & $\begin{array}{l}\text { Contact angle } \\
\text { fdegrees) }\end{array}$ \\
\hline 1 & - & - & - & + & $\mathrm{H}_{2} \mathrm{O}$ & 55 \\
\hline 2 & - & - & + & - & $\mathrm{H}_{2} \mathrm{O}$ & 60 \\
\hline 3 & - & - & + & - & $\mathrm{CH}_{2} \mathrm{Cl}_{2}$ & 60 \\
\hline 4 & + & + & + & - & $\mathrm{H}_{2} \mathrm{O}$ & 30 \\
\hline 5 & + & + & - & + & $\mathrm{H}_{2} \mathrm{O}$ & $30^{b}$ \\
\hline 6 & + & + & - & + & $\mathrm{CH}_{2} \mathrm{Cl}_{2}$ & $35^{b}$ \\
\hline 7 & + & - & + & - & $\mathrm{H}_{2} \mathrm{O}$ & 34 \\
\hline 8 & + & - & + & - & $\mathrm{CH}_{2} \mathrm{Cl}_{2}$ & 38 \\
\hline 9 & + & - & - & + & $\mathrm{CH}_{2} \mathrm{Cl}_{2}$ & $45^{b}$ \\
\hline
\end{tabular}

Table 2 Contact angles of Pell 80 A films washed with MeOH and modified with HEMA or MPEGMA-400

\begin{tabular}{lll}
\hline Monomer type & $\begin{array}{l}\text { Monomer concentration } \\
(\mathrm{mol} / \mathrm{l})\end{array}$ & $\begin{array}{l}\text { Contact angle } \\
\text { (degrees) }\end{array}$ \\
\hline HEMA & 0 & $50 \pm 5$ \\
HEMA & 0.05 & $32 \pm 3$ \\
MPEGMA-400 & 0.10 & $30 \pm 3$ \\
MPEGMA-400 & 0.05 & $44 \pm 7$ \\
\hline
\end{tabular}

anitial monomer concentration.

Table 3 Capillary rise in Pell 804 tubings

\begin{tabular}{llll}
\hline Tubing & Modified with & Height $(\mathrm{cm})$ & $\begin{array}{l}\text { Contact angle } \\
\text { [degrees) }\end{array}$ \\
\hline Pell 80A & - & 0.2 & n.d. \\
Pell 8OA & PEO/DCP & 0.2 & n.d. \\
Pell 8OA & MPEGMA-400 & 0.1 & n.d. \\
Pell 8OA-MeOH & - & 0.3 & n.d. \\
Pell 8OA-MeOH & PEO/DCP & 3.3 & 30 \\
Pell 8OA-MeOH & MPEGMA-400 & 3.5 & 27 \\
\hline
\end{tabular}

${ }^{a}$ n.d. $=$ not determined.

of the water column $h$, a value for $\theta$ of approximately $30^{\circ}$ could be calculated.

\section{Platelet deposition studies}

The results of the platelet deposition studies with perfusate A (buffer) are given in Figure 1. It shows that washing with methanol resulted in an increased platelet deposition. For both Pell $80 \mathrm{~A}-\mathrm{MeOH} / \mathrm{PEO} / \mathrm{DCP}$ and Pell $80 \mathrm{~A}-\mathrm{MeOH} /$ MPEGMA-400, low amounts of deposited platelets were found with values close to the detection limit of our test system.

Figure 2 shows the results of the platelet deposition studies with perfusate B (citrated plasma). For Pell $80 A$, Pel

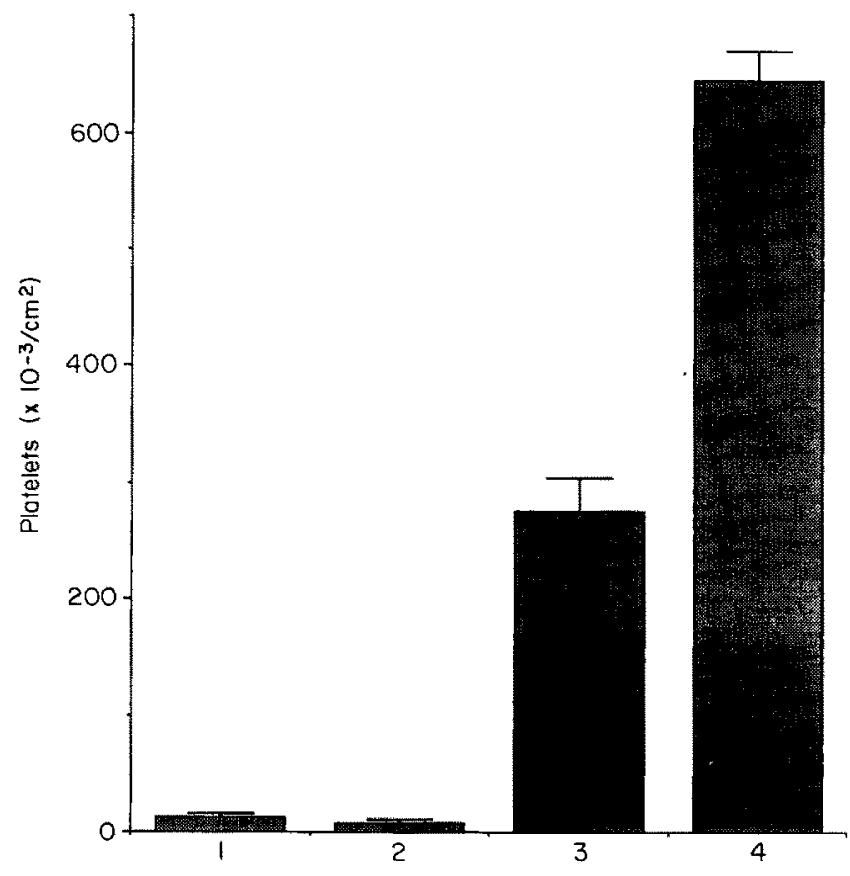

Figure 1 Platelet deposition to Pell 80A-MeOH/PEO/DCP (1) Pell 80A-MeOH/MPEGMA-400 (2). Pell 80A (3) and Pell 80A-MeOH (4) Perfusate A (buffer) 


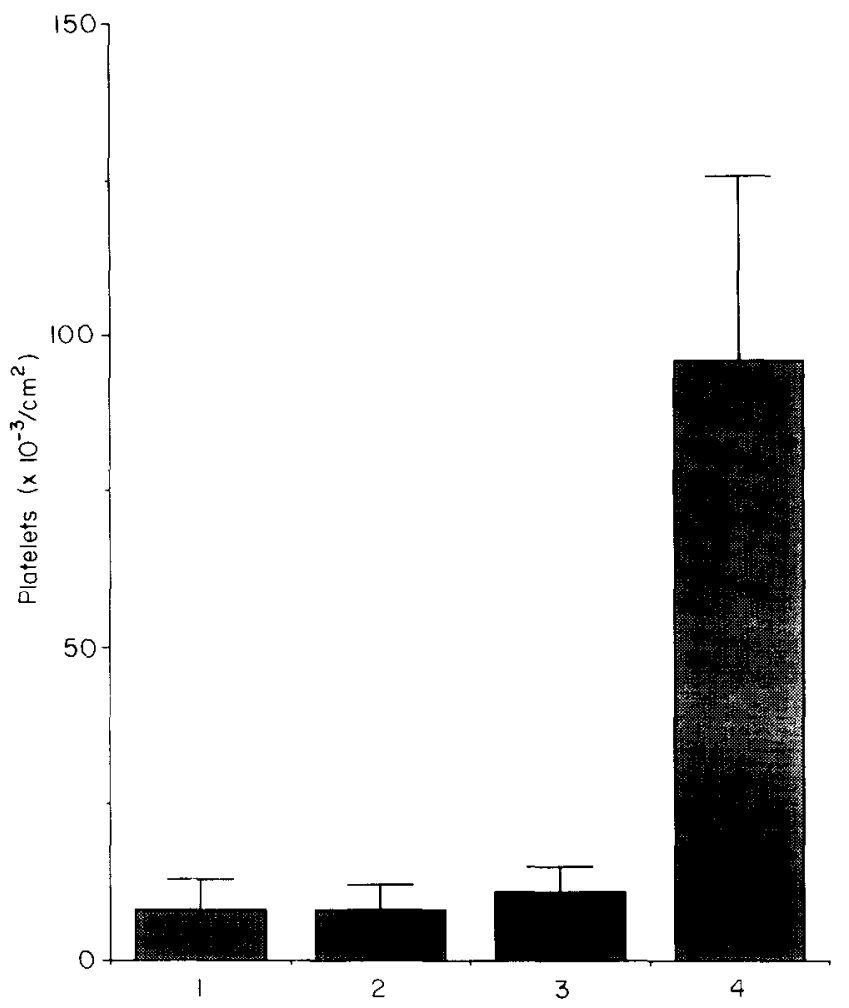

Figure 2 Platelet deposition to Pell 80A-MeOH/PEO/DCP (1) Pell $80 A$ (2), Pell 8OA-MeOH (3) and poly (ethylene) (4). Perfusate B (citrated plasma).

80A-MeOH and Pell 80A-MeOH/PEO/DCP, the same low amounts of deposited platelets were found.

The values for deposited platelets obtained with perfusate $\mathrm{C}$ (citrated plasma plus $\mathrm{Ca}^{2+}$ ionophore) were divided by the value observed for Pell $80 \mathrm{~A}$ resulting in ratios of platelet deposition as presented in Figures 3 and 4. Platelet deposition to Pell 80A and Pell 80A-MeOH/PEO/ DCP was low compared to poly(ethylene) (Figure 3). However from Figure 4, it is clear that, in these experiments, platelet deposition on Pell 80A was a factor of 5 higher than on Pell 8OA-MeOH/PEO/DCP. Again, washing with methanol resulted in increased platelet deposition.

\section{DISCUSSION}

\section{Surface modification of Pellethane 2363 80A}

Modification of Pellethane films and tubings was attempted to obtain more hydrophilic surfaces. In the first method, Pell 80A films were dipped in a PEO solution with or without DCP, then UV irradiated or thermally treated. Grafting should result in a weight increase of the films, but after treatment of the films, no significant increase in weight was observed. However, because the PEO-treated films showed a decrease of contact angle, this effect was supposed to indicate that grafting had still taken place.

From Table 1, it can be concluded that, using UV irradiation, grafting of PEO had occurred (experiments 4, 7 and 8). Table 1 also shows that a thermal treatment of PEO/DCP dipped films resulted in good wettable surfaces (experiments 5 and 6). However, grafting of PEO was also observed when DCP was absent (experiments 7,8 and 9). This phenomenon is difficult to explain for the thermally treated films, since formation of chemical cross-links in the absence of DCP is unlikely for a thermal process.

The second method was based on the graft poly-

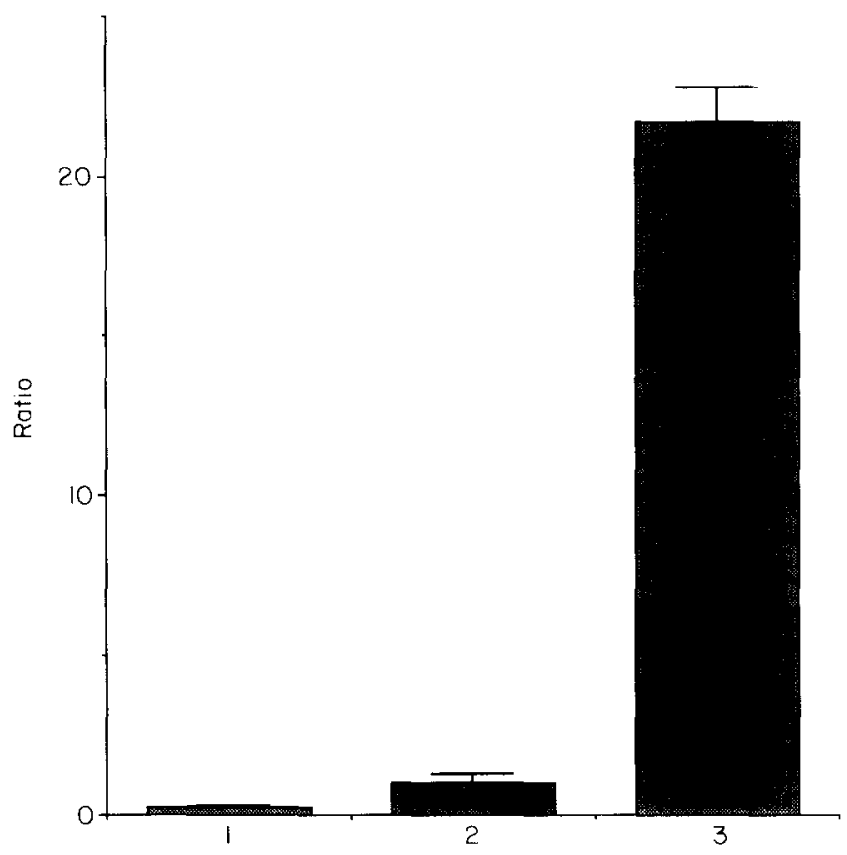

Figure 3 Ratios of platelet deposition to Pell 8OA-MeOH/PEO/OCP (1), Pell 80A (2) and poly(ethylene) (3). Perfusate C (citrated plasma plus $\mathrm{Ca}^{2+}$ ionophore).

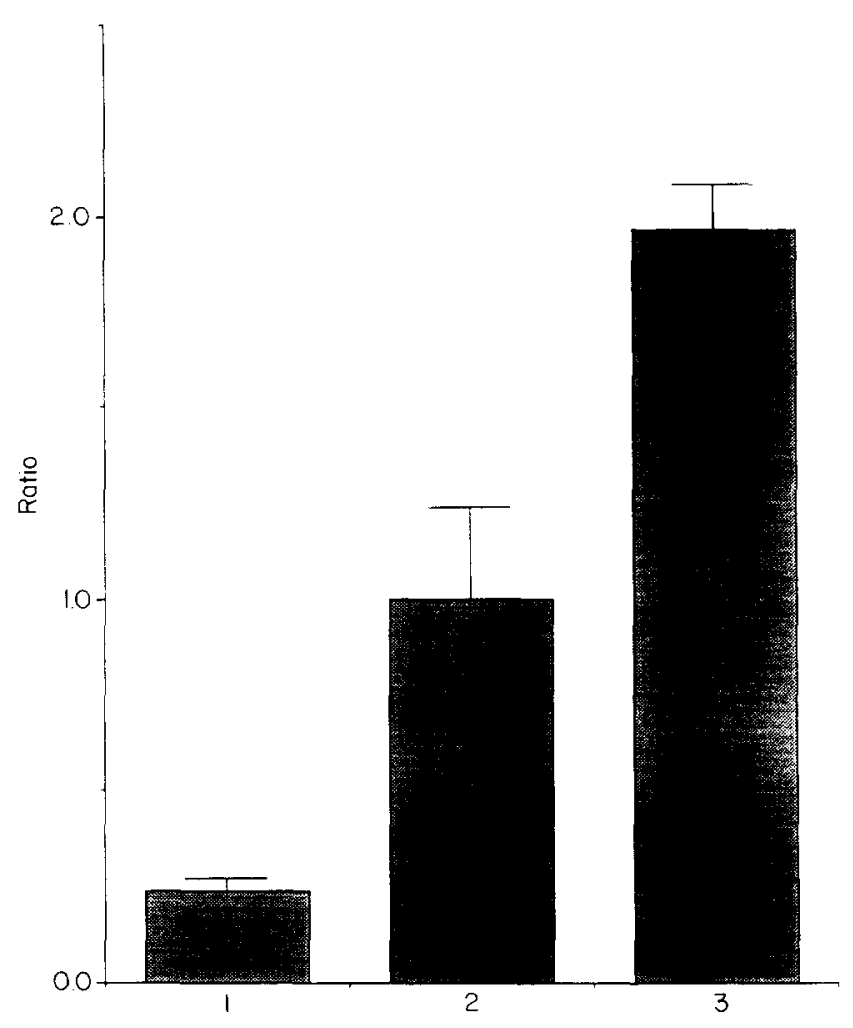

Figure 4 Ratios of platelet deposition to Pell 80A-MeOH/PEO/DCP (1), Pell 8OA (2) and Pell 8OA-MeOH (3). Perfusate C (citrated plasma plus $\mathrm{Ca}^{2+}$ ionophore).

merization of a methacrylate derivative of poly(ethylene glycol) with the controlled oxidation technique. Our results indicate that, with this technique, HEMA can be grafted on to Pell 80A films even at low initial monomer concentrations (0.05-0.10 M). Using this concentration range, no weight increase of the films could be measured, but a strong decrease in contact angle compared to unmodified Pell 80A films was observed (Tab/e 2). Grafting with MPEGMA-400 
also resulted in good wettable surfaces. In contrast to the experiments with HEMA, the contact angle of the films modified with MPEGMA-400 depended on the initial monomer concentration in the concentration range used.

The experiments with the Pell $80 \mathrm{~A}$ tubings show that modification with PEO/DCP (thermally induced grafting) as well as graft polymerization of MPEGMA-400 lead only to more hydrophilic surfaces when the tubings are washed with methanol before the treatment (Table 3).

\section{Platelet deposition studies}

The platelet deposition to the luminal side of Pell 80A tubings was studied, to evaluate the effect of grafted PEO on blood compatibility. Using a capillary flow system, the interaction of platelets with artificial surfaces was investigated under conditions of laminar flow and physiological shear rates. Buffer and plasma were applied as a suspending medium for the platelets and red cells in the perfusate. Since platelet deposition in vivo is always preceded by protein adsorption, it seems more relevant to study platelet deposition in vitro with plasma-containing perfusates. However, when plasma is used, the employed anticoagulant may influence platelet deposition. Our findings with different types of perfusate show that the platelet deposition depends on both the biomaterial and the type of perfusate.

When platelets and red cells were resuspended in buffer, platelet deposition to Pell 8OA-MeOH/PEO/DCP and Pell 80A-MeOH/MPEGMA-400 was negligible and less than on Pell 80A (Figure 1). This favourable effect upon platelet deposition might be explained in terms of an increased hydrophilicity of the surfaces, because, after modification of Pell 8OA-MeOH with PEO/DCP or MPEGMA-400, the air-water contact angle had decreased from 55 to $60^{\circ}$ to approximately $30^{\circ}$. However, besides the increased hydrophilicity, the inertness of PEO itself and/or the high mobility of PEO chains in water may play a role ${ }^{3.7}$. Considering the results of Figure 1 , it seems that both surface modifications, grafting with $P E O / D C P$ and graft polymerization of MPEGMA-400, have the same favourable effect on platelet deposition. Because grafting of PEO with DCP was the most easy to handle, we decided to focus our attention on this surface modification technique.

Experiments with platelets, resuspended in citrated plasma (Figure 2), showed that platelet deposition to Pell 80A-MeOH/PEO/DCP and Pell 80A was almost absent. A low platelet deposition to Pell $80 \mathrm{~A}$ from a plasma-containing perfusate might be ascribed to favourable protein adsorption. However, lower values for platelet deposition from a perfusate might be ascribed to a favourable protein adsorption. influenced by the anticoagulant. Citrate binds extracellular calcium and this may affect platelet functions ${ }^{17}$.

For this reason, $\mathrm{Ca}^{2+}$ ionophore was added to the perfusate to increase the sensitivity of the test system. $\mathrm{Ca}^{2+}$ ionophore increases intracellular calcium levels, thereby activating the platelets ${ }^{18}$. Again the platelet deposition to Pell 80A-MeOH/PEO/DCP was negligible, but an increased platelet deposition to Pell 80A was found (Figures 3 and 4). Thus, in experiments with perfusates containing citrated plasma, small differences in the reactivity of biomaterials towards platelets might be masked by the presence of citrate.

A comment should be made on the increased platelet deposition to Pell 80A after rinsing with methanol. As discussed before, this washing procedure was an essential condition for a good grafting of PEO and MPEGMA-400 on the luminal side of Pell 80A tubings. However, in control experiments with Pell $80 A$ films, it turned out that grafting of MPEGMA-400 also occurred on unwashed films. It seems that methanol extraction changes the surface structure of Pell 80A tubings either by re-orientation or removal of components from the surface. In this respect, it must be mentioned that Ratner and Paynter ${ }^{15}$ and Briggs ${ }^{16}$ pointed to the fact that Pell 80A contains stearamides as an extrusion lubricant. It is assumed that these agents migrate towards the polymer surfaces during a heat treatment ${ }^{19}$. As a consequence, stearamides can dramatically affect the surface properties of extruded Pell $80 \mathrm{~A}$ tubings. Removal of these contaminants by methanol extraction obviously resulted in differences in platelet deposition to Pell 80A and Pell 80A$\mathrm{MeOH}$, respectively.

\section{CONCLUSIONS}

Pell 80A films and tubings, prerinsed with methanol, were modified by grafting high molecular weight $P E O$ or by graft polymerization of MPEGMA-400. Depending on the experimental conditions a decrease in contact angle from 55-60 to approximately $30^{\circ}$ was found. With a buffer-containing perfusate, tubings of Pell 80A modified with PEO/DCP or MPEGMA-400 showed a marked reduction in platelet deposition compared to unmodified Pell $80 \mathrm{~A}$ tubings. Platelet deposition to Pell $80 \mathrm{~A}$ tubings modified with $\mathrm{PEO} / \mathrm{DCP}$ also decreased when a perfusate containing plasma was used.

\section{ACKNOWLEDGEMENTS}

This work was supported in part by STW. The Netherlands Foundation of Technology.

\section{REFERENCES}

1 Whicher, S.J. and Brash, J.L., Platelet-foreign surface interactions: Release of granule constituents from adherent platelets, J. Biomed. Mater. Res. 1978, 12, 181-201

2 Mori, Y., Nagaoka, S., Takiuchi, H., Kikuchi, T., Noguchi, N., Tanzawa, H. and Noishiki, Y., A new antithrombogenic material with long polyethylene oxide chains, Trans. Am. Soc. Arif. Int. Org. 1982, 28, 459-463

3 Nagaoka, S., Mori, Y., Takiuchi, H., Yokota, K., Tanzawa, H. and

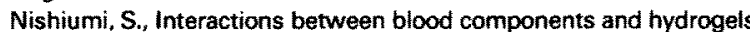
with poly(oxyethylene) chains, in Polymers as Biomaterials, (Eds S.W. Shalaby, A.S. Hoffman, B.D. Ratner and T.A. Horbett), Plenum Press, New York. 1984, p 361

4 Bots, J.G.F., Does, L. van der and Bantjes, A., Small diameter blood vessel prostheses from blends of poly(ethylene oxide) and poly(propylene oxide), Biomoterials 1986, 7, 393-399

5 Sa da Costa, V, Brier-Russell, D. Trudel, G., Waush, D.F, Salzman, E.W. and Merrill, E.W. Polyether-polyurethane surfaces: thrombin adsorption, platelet adsorption, and ESCA scanning, J. Coll. Interf. Sci. $1980,76,594-596$

6 Sa da Costa, V., Brier-Russell, D., Salzman, E.W. and Merrill, E.W., ESCA studies of polyurethanes: Blood platelet activation in relation to surface composition, J. Coll. Interf. Sci. 1981, 80, 445-452

7 Merrill, E.W., Salzman. E.W. Dennison, K.A., Tay, S.W. and Pekala R.W., Non-adsorptive hydrogels for blood contact, in Progress in Artificial Organs, (Eds Y. Nosé, C. Kjelistrand and P. Ivanovich), ISAO Press, Cleveland, 1986, p 909

8 Bots, J.G.F., Does, L. van der, Bantjes, A. and Lutz, B., Polyethers for biomedical applications: Bulk and surface characterisation of crosslinked blends of poly(ethylene oxide) and poly(propylene oxide), $B r$. Polymer J. 1987, 19, 527-533

9 Brinkman, E., Poot, A., Beugeling. T., Does, L. van der and Bantjes, A. Surface modification of copolyether-urethane catheters with poly(ethylene oxide). Int. J. Art. Organs 1989, 12. 390-394 
10 Feng, X.D., Sun, Y.H. and Qiu, K.Y., Selective grafting of hydrogels onto multiphase block copolymers, Makromol. Chem. 1985, 186 1533-1541

11 Poot, A., Beugeling, T., Cazenave, J.P., Bantjes, A. and Aken, W.G. van, Platelet deposition in a capillary perfusion model: quantitative and morphological aspects, Biomateria/s 1988, 9, 126-133

12 King, R.N., Andrade, J.D. and Ma, S.M., Interfacial tensions at acrylic hydrogel-water interfaces, $J$ Coll Interf. Sci, 1985, 103, 62-75

13 Cazenave, J.P., Mulvihill, J.N., Huisman, J.G. and Aken, W.G. van, The use of monoclonal antibodies against platelet membrane glycoproteins to measure platelet accumulation on artificial surfaces, in Biology and Pathology of the Platelet: Vesse/ Wall Interactions, (Eds G. Jolles, Y. Legrand and A. Nurden), Academic Press, New York, $1987, \mathrm{p} 375$

14 Cazenave, J.P., Hemmendinger, S., Beretz, A., Sutter-Bay, A. and Launay, J., Lagrégation plaquettaire: outil d'investigation clinique et d'étude pharmacologique, Méthodologie, Ann. Biol. Clin. 1983, 41. 167-179
15 Ratner, B.D. and Paynter, R.W., Polyurethane surfaces: The importance of molecular weight distribution, bulk chemistry and casting conditions, in Polyurethanes in Biomedical Engineering, (Eds G. Planck, G. Egbers and I. Syre), Elsevier, Amsterdam, 1984, p 41

16 Briggs, D., Analysis and chemical imaging of polymer surfaces by SIMS, in Polymer Surfaces and Interfaces, (Eds W.J. Feast and H.S. Munro), John Wiley Sons Ltd, New York, 1987, p 47

17 Kinlough-Ratbone. R.L., Mustard, J.F., Packham, M.A., Perry, D.W Heimers, H.J. and Cazenave, J.P., Properties of washed human platelets, Thromb. Haemost. 1977, 37, 291-308

18 Worner, P., Interactions of platelet activating pathways: studies with cations, ionophores and agents with group specificity, in Platelet Responses and Metabolism, Volume I: Responses, (Ed. H. Holmsen), CRC Press Inc., Boca Raton, 1986, p 285

19 Ulrich, H., Bonk, H.W. and Colovos, G.C., Synthesis and biomedical applications of polyurethanes, in Synthetic Biomedical Polymers, (Eds N. Szycher and W.J. Robinson), Technomic, Westport, Connecticut, 1980 , p 29 